\title{
Expanding of spheres the application of borehole hydro-production technology to develop deposits of non-traditional hydrocarbons
}

\author{
Mykhailo Pedchenko ${ }^{1 *}$, and Larysa Pedchenko ${ }^{1}$ \\ ${ }^{1}$ Poltava National Technical Yuri Kondratyuk University, Department of Oil and Gas Exploitation \\ and Geotechnics, 24 Pershotravnevyi Ave., 36011 Poltava, Ukraine
}

\begin{abstract}
The reserves of oceanic hydrates of methane and natural bitumen in times exceed the stocks of traditional oil and gas. The purpose is the analysis of the adaptation possibility of borehole mining technology for the development of bituminous sands deposits and marine gas hydrates was the purpose of the study. The variants of the HBM technology adaptation for the development of bituminous sands and gas hydrates deposits are proposed. The method of extracting gas hydrates based on HBM technology involves them removal without the energy consumption for phase transition. The main advantages of the development of bituminous sands deposits on the basis of HBM technology are: the possibility them extraction in the range of depths $75-200 \mathrm{~m}$, the potential high rate of bitumen extraction, the separation of bitumen from the rock in production, the minimum impact on the environment, the possibility of conducting extraction of natural bitumen in areas covered with water.
\end{abstract}

\section{Introduction}

The trend of long-term depletion of world stocks of traditional fuels has actualized for the world community the problem of further study of the resource potential of non-traditional sources of hydrocarbons [1,2]. Oil of bituminous sands, coal methane, shale gas, shale oil and gas hydrates are unconventional sources of hydrocarbon raw materials. All these resources are explored or developed by companies all the world. However, based on explored stocks, oceanic methane hydrates and natural bitumen have particular importance for humanity [3 -5]. Their stocks are more than the stocks of traditional oil and gas. All geological preconditions for the formation of large industrial clusters of high-viscosity oil, natural bitumen and marine gas hydrates are in Ukraine. According to preliminary estimates, total methane volumes accumulated in natural ocean hydrates are estimated at the level of $2.1 \cdot 10^{16} \mathrm{~m}^{3}$ [6]. According to the French Institute of Petroleum, geological reserves of heavy oil and bitumen of all categories are estimated at 4.7 trillion barrels in oil equivalent. Among them, about 1 trillion are recoverable, which is roughly equal to the world resources of conventional oil.

\footnotetext{
${ }^{*}$ Corresponding author: pedchenkomm@ukr.net
} 


\section{Gas hydrates and methods for extracting of natural gas from gas hydrate deposits}

Gas hydrates are clathrate compounds or combinations of inclusion. In appearance they are like thick snow. In $1 \mathrm{~m}^{3}$ of natural gas hydrate contains about $160 \mathrm{~m}^{3}$ of methane [7]. Underwater gas hydrates can form clusters on the seabed, a small pallet depth (first meters) or at a depth of hundred meters from the bottom.

The development of gas hydrate deposits can is carried out by a quarry method or free gas can is selected through wells after dissociation of the hydrate in the reservoir. Dissociation of hydrate to gas and water can be carried out by the following ways: lowering the pressure below equilibrium for hydrate formation, raising the temperature higher than equilibrium, injection of the substance-inhibitors for the process into the reservoir, or combination of the above methods. Significant energy costs are a disadvantage of thermal methods. In addition, the zone of thermal action in the reservoir will be limited to several meters.

In terms of energy costs, the way to reduce the formation pressure below equilibrium with the subsequent selection of free gas is most acceptable. However, in this way, secondary hydrate's formation will be observed in the prebottom of the well.

Gas hydrates can also serve as a "cement" for rock particles. In this case, the melting of the gas hydrate will lead to abnormally high porosity, the separation of large water masses and a significant reduction in the strength of the productive layer [6]. The removal of a significant amount of rock in the well will be observed as a result, which will interfere with its exploitation.

Methods of career development will be complicated by the fact that the bottom deposits of gas hydrate is mainly covered with a layer of deposits in several meters [8]. Also, this method will be effective only at significant content of gas hydrates in the rock. At present, industrial development of gas hydrates deposits is not conducted in the world due to lack of efficient and competitive technology.

\section{Natural bitumens and methods of their extraction}

Alternative to conventional crude oil is oil sands which (tar sands or bituminous sands). Oil sands are a loose sand deposit which contain a very viscous form of petroleum known as bitumen. These unconsolidated sandstone deposits comprise primarily of sand, clay and water saturated with bitumen. A typical oil sands deposits contains about $10 \%$ bitumen, 5\% water and $85 \%$ solids. The largest world deposits are in Canada, Venezuela, Madagascar, USA and Russia [9]. In spite of the high energy consumption required in extraction of bitumen from tar sand, it is an economically viable enterprise and it is being undertaken in vast tar sand deposits in Canada. The majority of these reserves are found in Alberta's oil sands - over 174 billion barrels.

There are two basic methods of bitumen extraction used in the oil sands: surface mining and in-situ. The method used depends on the depth of the reservoir. The most effective way of extracting significant deposits of bituminous sands that lie at a shallow depth is the quarry. Deposits located at a depth of less than $75 \mathrm{~m}$ can technically be surface mined, although most deposits are located at a depth of less than $50 \mathrm{~m}$ below grade. It is widely distributed in Canada, where up to $20 \%$ of proven bitumen reserves lie in sandy collectors at a depth of $50 \mathrm{~m}$.

The first stage mining by open method is the removal of a peat layer and rock $2-6 \mathrm{~m}$ thick. Preliminary the area is drained. The process can continue up to 3 years. The ore is dug up and mixed with warm water to separate and recover the bitumen from the sand. The separation takes place in separation cells. The combination of hot water and agitation 
releases bitumen from the oil sand, and causes tiny air bubbles to attach to the bitumen droplets, that float to the top of the separation vessel, where the bitumen can be skimmed off. Further processing removes residual water and solids. Bitumen normally requires dilution with lighter hydrocarbons to make it transportable by pipelines. The bitumen is then transported and eventually upgraded into synthetic crude oil.

This process recovers about $90 \%$ of the bitumen. The remaining $80 \%$ of the bitumen is too deep to be mined and can only be extracted in-situ. A number of methods for bitumen smelting in situ of bedding are developed in this regard. Most in-situ bitumen and heavy oil production comes from deposits buried more than 400 meters below the surface of the earth. Given the physical and chemical properties of natural bitumen, the application of methods that maximally reduce their viscosity, is the most rational. Among a such methods, thermal and thermochemicals occupy a special place. These involve different combinations of injecting steam or solvents through horizontal or vertical wells.

The first promyslovoyu tehnologiyehu becoming a method CSS (Cyclic Steam Stimulation). In this process, steam is added to the oil sands via vertical wells, and the liquefied bitumen is pumped to the surface using the same well. Steam at a temperature above $300{ }^{\circ} \mathrm{C}$ is pumped over several months. Then a well is heated for several weeks. After that, heated bitumen can is pumped during for several months. However, the process can be cost-effective only for the first few cycles (usually $3-5$ ). This method allows to extract up to $25 \%$ bitumen, what contained in the sand.

The Steam-Assisted Gravity Drainage (SAGD) technology is believed one with the most effective and applicable. For implement SAGD, two horizontal wells are drilled (one over the other at a distance of $3-7 \mathrm{~m}$ ). The steam is served during 90 days into the well and creates a warmed area, reducing the viscosity of bitumen (oil) and increasing mobility. The force of gravity directs condensed water and mobile hydrocarbons (bitumen) to the bottom of the mining well. In the second phase, the extraction of bitumen (high viscosity oil) is carried out from the extraction wells and steam is pumped into the inqection well. But at the same time the roof of the productive layer should be a reliable barrier to prevent the loss of steam. SAGD has demonstrated that its operations can recover as much as $60 \%$ of the bitumen inplace. SAGD wells operate at low vapor pressures. Steam Assisted Gravity Drainage (SAGD) is currently the most commonly used in situ recovery method.

"Cold" methods of bitumen extraction also exist and they predict instead of steam pumping bitumen is processed by the dissolvent in the layer (VAPEX method). This method is also implemented using two horizontal wells. A dissolvent (hydrocarbon dissolvents including ethane or propane) is pumped into the upper well instead steam. Bitumen is rarefied due of the dissolvent diffusion in it and flows to the mining well under the action of gravitational forces. This method requires no water and is $25 \%$ lower in capital costs than the SAGD process. Operating costs are half that of the SAGD process [10].

Also commercial efficiency of the extraction method using dissolvents in a vapor state (VAPor EXtraction - VAPEX) is justified. Hot ethanes and propane-butane are pumped into the well located at the top of the formation. Reduced viscosity of bitumen is achieved by heating and rarefing by the dissolvent, as a resulting in a mixture of bitumen-dissolvent gravity drains down into the mining well. Due to the using of hydrocarbon solvents it is possible to significantly reduce energy costs, as well as successfully develop collectors with high content of clay, where the using of the stea's method is unacceptable. The coefficient reaches $60 \%$, however, the rate of extraction is extremely low.

The new technology, N-Solv, is a modification of the VAPEX method. The technology uses propane heated to $50{ }^{\circ} \mathrm{C}$. It requires $80 \%$ less energy, and propane can be reused. The dissolvent dissolves bitumen, and the hardest components remain underground. The resulting product returns out less viscous and can be transported immediately along the oil pipeline. The efficiency of the process has been greatly increased by removing of the 
methane admixture from propane. Methane in the reservoir significantly degrades the heat exchange process at the boundary of the bitumen - dissolvent.

At present, the processes co-injection of vapor and dissolvent are also used: improved steam-gravity effect by the dissolvent - Expanding Solvent SAGD (ES SAGD), Process with addition of the dissolvent (SAP), alternating of reinqection dissolvent and vapor Steam Alternating. However, the main problem with the injection of water vapor or hydrocarbon dissolvents is the heterogeneity of productive layers. This inevitably leads to their breakthrough to producing wells and the need to use flow-deflecting technologies (blocking gels, sediment-forming compositions).

The thermal methods for the development of bituminous sands also include the method of electric heating. This technology, as a rule, is used as an auxiliary in the implementation of SAGD and the development of deposits in a career way [11].

CHOPS technology [12] involves the "cold" extraction of heavy oil along with sand. For this purpose, depression is created in the layer. So-called "wormholes" are formed due to the destruction of weakly cemented rocks. Oil and sand by them come to the well. The CHOPS method is widely used for oil production in Canada (up to $15 \%$ of total production). It does not require large investments for development and has low operating costs. But the oil recovery ratio does not exceed 20\%. Also, CHOPS requires constant monitoring, as conditions are constantly changing at the bottom.

Thus, the lower boundary of the career development of bituminous sands is a depth of $75 \mathrm{~m}$. Methods for extracting bitumen in site of it occurrence are applied starting at a depth of $200 \mathrm{~m}$ due to the danger of a break through of the working agent on the surface. Therefore, the interval of bedding of the bituminous sands, for which there is not effective technology of their extraction, exists. In this regard, the important task is to develop an effective method for this interval of bedding of bituminous sands.

At first glance, the extraction technology of gas hydrates and natural bitumen must be significantly different. However, they are united by the fact that in the natural bedding the solid gas hydrate and viscous or hard bitumen do not exhibit fluid properties. Their mobility first of all affects extraction. For this, for example, a significant amount of thermal energy is introduced into the system. As a result, the gas hydrate dissociate into gas and water, and the viscosity in bitumen decreases. In terms of project effectiveness, it is better to do it in situ of their bedding.

\section{Analysis of the features of hydraulic borehole mining the technology}

Physical and chemical technology of hydraulic borehole mining (HBM) minerals is well known in mining. The cutting of a specific rock type is dependent on a multitude of factors involving both the physical properties of the rock and tool operating parameters. The primary cutting mechanism in a HBM system is the conversion of kinetic energy of the water jet into impact pressure, acting on the rock face. The technology involves the destruction of the rock in situ of it occurrence due to the hydraulic energy of the fluid jet, the formation of hydro-mixture (pulp) and it extraction on the surface [13]. Penetrating into an array due to filtration in pores and cracks, water reduces the strength of rocks, causing local hydrodynamic fractures and destruction [14 - 16]. In a flooded bottom, the technology allows to develop of non-bonded ore bodies in conditions of large water inflow, as well as under water and on the shelf of the seas.

However, the rapid dissipation of the energy of the jet occurs in condition a flooded bottoml [17]. Using of hoses or telescopic monitors lengthening as the bottom moves, is required. This complicates the design of the unit, requires the creation of special systems for monitoring and controlling the hydraulic monitor. At the same time, the amount of work 
for one well is limited in connection with the threat of collapse of the roof. After the collapse, the extended hydraulic monitor is difficult or impossible to remove. At the same time extraction of rock mass is difficult and exist high level of losses. All this limits the sphere of application HBM technological scheme.

However, the analysis of the characteristics of the HBM technology allows us to conclude that it is expedient to use for the development of bituminous sands deposits and marine gas hydrates. Therefore, the analysis of the adaptation possibility of borehole mining technology for the development of bituminous sands deposits and marine gas hydrates was the purpose of the study.

\section{Features of the development of gas-hydrate deposits by the method of HBM}

The above advantages and disadvantages of the HBM technology are taken into account in the method of developing marine deposits of gas hydrates (Fig. 1) [16].

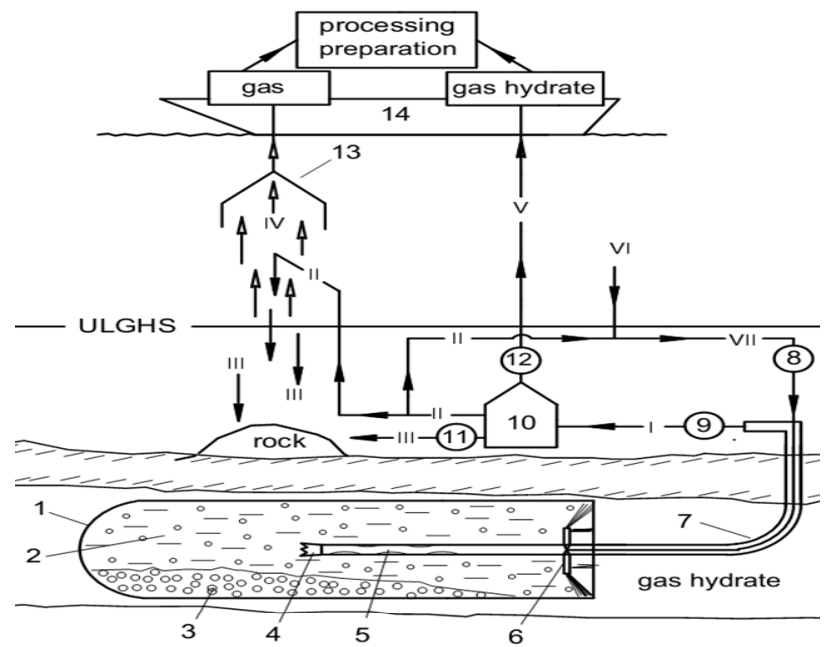

Fig. 1. Principal diagram of the method for marine gas hydrate deposits development: ULGHS - the upper limit of gas hydrate stability; 1 - excavation in the hydrate-saturated reservoir; 2 - space in the excavation site filled water-hydrate mineral pulp; 3 - sediment of rock solid inclusions; 4 - drill bit; 5 pulp intake; 6 - jet gun device; 7 - well; 8, 9, 11, 12 - pump; 10 - gravity separator; 13 - gas collecting dome; 14 - production platforms; streams; I - water-hydrate mineral pulp; II - gas hydrates depleted pulp; III - empty rock; IV - gas released from the pulp as a result of gas hydrate dissociation; V - water gas hydrate mixture; VI - sea water; VII - working fluid for rock disintegration (sea water and pulp mixture).

The next sequence of technological operations is a feature of the proposed method of technical and technological decisions:

- drilling wells to maximum length;

- formation of a chamber on a bottom well hole for opening of a rod with nozzles of hydraulic monitors in working position;

- destruction of the rock with flooded jets and the formation of mining.

The decisive parameter in the energy transfer mechanism from the jet to the breed is the distance between them. Therefore, rods with hydromonitors rotate around the axis of the column, gradually approaching the front of destruction.

This method involves: 
- destruction of the rock of the gas hydrate formation and it transfer into the composition of the pulp;

- preliminary enrichment of the pulp on the gas hydrate in the development as a result of gravitational separation of the fragments of rock and gas hydrate;

- separation on the seabed from a pulp of the gas hydrate in a gravity separator;

- dissociation of the residual gas hydrate in the impoverished pulp due to the thermal energy of sea water;

- supply of gas hydrate and gas to the extraction platform.

The dissipation of a large part of the jet energy will be observed in the hydrodynamic action in the process of HBM. In addition to increasing the flow temperature of the fluid in the pumps and the piping system, part of the energy will turn into heat at the moment of jet impact on the rock. However, the gas hydrate in the deposit is at a certain level of supercooling relative to equilibrium conditions. This is a condition for the existence of gas hydrates deposits. However, this overcooling is insignificant - it is several degrees. The local area heating will certainly be formed on the boundary of rock destruction by the jet. It is assumed that it will be limited by a few millimeters and will not go beyond the contour of the flow contact with the rock. Thermal energy in this zone will be spent on the increase of temperature including gas hydrate. Moreover, the allocated energy will be enough to disassociate its parts into gas and water. In addition, the gas hydrates in the rock can fulfill the function of it cement. Therefore, their melting on the boundary of the array and mining will positively affect the effectiveness of the technology. Thus, in the gas hydrates production by the method HBM, the heat energy of the dissipative processes will positively influence the efficiency of the disintegration of the rock saturated with gas hydrates. Also, according to the law of energy conservation, going beyond the boundaries of local zones heat energy, gas again enters to the conditions for the stability of the gas hydrate. Repeat formation of hydrate will occur as a result. Hence, hydraulic fracturing will be accompanied by recrystallization of a part of the gas hydrate. And melting occurs in the one situ, and the formation - in another (in the formed pulp). And most likely, the it overwhelming part will be separated from the rock particles.

In addition, the zone of pulp gravity separation will exist in the development of a certain distance from the zones of destruction and turbulent mixing of the pulp. Here, the fragments of the rock will fall into the precipitate, and the gas hydrate (natural and recrystallized) will fall to the cluster of excavation. (And it is here that it is supposed to place its pumping hopper to the extractive platform). Thus, the initial enrichment of the target product will occur even in the excavation. That is, there will be no need for the costs of lifting and subsequent operations with most of the breed ballast.

It also in mind that the method described in [18] Involves the use in the process of seawater (known mineralization). And the volume of the hydro-monitor flooded jet before the moment of reaching the destruction front will increase due to the addition of the pulp part together with particles of the breed [13]. In this case, the salts of sea water in the zone of the rock destruction will act as a inhibitor of the hydrate process, and grain of the rockan abrasive material. All this will further increase the efficiency of this technology.

In addition, the proposed method for the development of gas hydrate deposits will allow the direct removal of gas hydrate without the energy consumption for phase transition. It is further assumed that on the extraction platform, the recovered gas hydrate will be recycled in accordance with the technology proposed in [19] for further transportation and storage. Given the enthalpy of hydrate formation $(540 \mathrm{~kJ} / \mathrm{kg})$, this technology will have significant competitive advantages over methods that provide for it dissociation in the formation and extraction of gas. 


\section{Features of the development of bituminous sands deposits by the method of HBM}

Taking into account the properties and features of the bituminous sands bedding, the technology described above for the development of gas hydrate deposits [18] can be adapted to extract bitumen from bituminous sands deposits. The technology based on HBM and adapted for bitumen mining is presented in Fig. 2. In essence, the main difference between this version of the technology is the heating of water before feeding it to the hydro-monitor and adding of the surface-active substances. That is, in addition to the rock destruction and the underground mining formation, the method involves bringing to it heat energy for reduce the viscosity of bitumen.

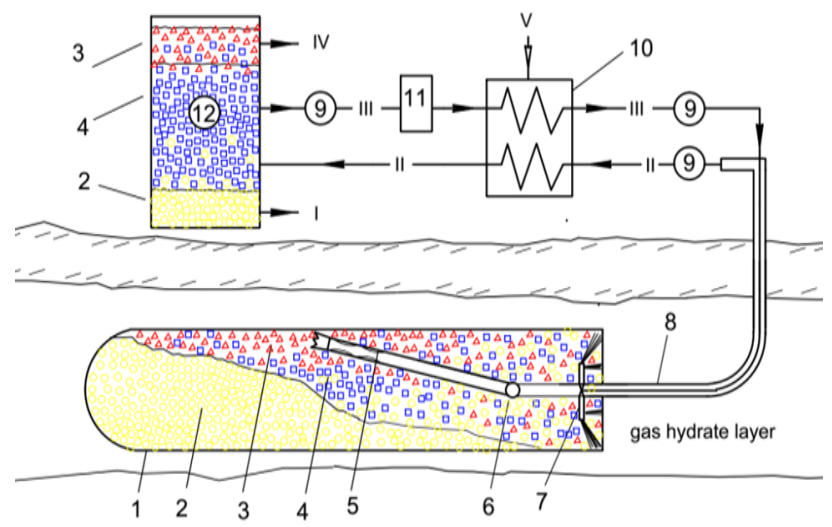

Fig. 2. Scheme of a method for the bitumen extraction from deposits of bituminous sands based on the technology of HBM: 1 - development; 2 - sand sediment; 3 - pulp enriched on bitumen; 4 water with clay fraction; 5 - a shank with a drilling bit and a pulp picker; 6 - hinge; 7 hydromonitoring device; 8 - well; 9 - pump; 10 - heating block; 11 - block of separation of solid phase; 12 - separator; streams: I - sand sediment; II - a pulp enriched with bitumen; III - clay solution; IV - bitumen; V - coolant.

The pressure of water for effective the rock crushing is within the range of 5-20 MPa. Given the phase equilibrium of the system "water - steam", its temperature can be increased to $400-500 \mathrm{~K}$. After the jet out of the nozzle, part of the energy will be transferred to the attached pulp mass [13].

It is also assumed that outside the hydraulic system, where the pressure corresponds to the formation (reservoir), the level of liquid overheating in the destructe zone will be sufficient for it boiling. Bubbles and cracks of the rock will be forming and growing in the pores, destroying ones. Therefore, this process will also have a positive impact on the effectiveness of the technology. As a result, after the disintegration of the rock, the pulp will have a composition and temperature similar to maintained in the separators of known sets of the bitumen separation from bituminous sand. In this case, mine excavation will act as a separator itself. Similarly to the known technology, in these "separators", the active the pulp mixing will be observed near the destruction zone of the rock by hydro-motors. At some distance from this zone of movement will fade away. The pulp gravitational separation will occur in this place: the pulp concentrate with a high content of the bitumen and clay fraction rock ascends, and rock particles of a larger size - will settle down to the bottom of the excavation. Enriched pulp will be pumped from the excavation to the surface. The bitumen will be separated from the pulp after a slight additional heating. Warm water (uncleaned, even with certain rock content) returns to the process again. Judging by the 
processes that take place in the development, the rate of bitumen extraction by this technology can compete with the career method. Taking into account also the relatively low thermal conductivity of the rock, the possibility of heat energy recuperation, low water consumption and a potentially high bitumen recovery rate, this technology will have high competitiveness.

Variant of the deposit development on the land is shown in Fig. 2. However, the bitumen extraction in this way can be conducted and in areas covered with water and marshes. Also, this method will not require drainage at the place, and thus shorten the start date of extraction. The pressure in the production will be close to the hydrostatic, so the breakthrough of the pulp on the surface is excluded. There will also be no restrictions of the rock characteristics for the roof of the productive layer. The duration of the preparatory operations will be negligible. The product selection will begin almost immediately after the delivery of the coolant to the hydro-monitors. Therefore, the heat loss in the adjacent layers of the rock will be minimal.

Given the potentially high withdrawal ratio, the cost of bitumen extraction by this method will be low. The technology promises significantly lower capital and operating costs than conventional mining. Major oil sands projects require substantive environmental assessments before they are approved. In Canada oil sands development is subject to environmental standards that are among the most stringent in the world. An analysis of the proposed method shows that the negative impact on the environment will be minimal.

\section{Conclusions}

1. Analysis of the borehole hydraulic mining processes, technological operations and the sequence them implementation showed the prospect of the introduction such a method for the development of bituminous sands and gas hydrates deposits.

2. The main advantage of the method for the development of gas hydrate deposits based on HBM technology is remove the target product (gas hydrate) from the productive layer without the energy consumption for the phase transition.

3. The method of development of gas hydrate deposits based on HBM technology can be easily adapted for the bitumen extraction from bituminous sands.

4. The advantages of developing bituminous sands deposits on the basis of borehole hydraulic mining are:

- the possibility them extraction in the range of depths $75-200 \mathrm{~m}$, where application other methods is problematic;

- potentially high coefficient of bitumen extraction, which will approach to the level of the career method;

- relatively low water consumption;

- minimal impact on the environment;

- similarly to the variant of marine gas hydrate deposits development, in this way it is possible to produce natural bitumen in areas covered with water (sea shelves, lakes), as well as in wetlands without drainage.

5. Hydraulic borehole mining can remove underground ore deposits tar sand that cannot be economically mined by the usual open pit or underground methods.

6. Selectivity of the borehole mining system also allows economical recovery of small or extraction ore deposits while minimizing the removal of host rock.

7. The development of technical solutions and refinement of the technology parameters requires research and industrial testing. Moreover, these decisions can differ significantly depending on the geological conditions of specific deposits. 
This work has become possible due to financial and organizational support within the frames of the state budget research project under the auspices of the Ministry of Education and Science of Ukraine "Application of gas hydrate technology in the development of traditional and gas hydrate gas deposits" (State registration No. 0113U00857), "Research of influence of thermodynamic parameters of phase transitions in systems with gas hydrates on the efficiency of gas hydrate technology" (State registration No. 0115U002420).

\section{References}

1. Shunko, V. (2015). Monograph "Unconventional hydrocarbon resources of Ukraine". Visnyk of Taras Shevchenko National University of Kyiv. Geology, (3), 79-80.

2. Bondarenko, V., Lozynskyi, V., Sai, K., \& Anikushyna, K. (2015). An overview and prospectives of practical application of the biomass gasification technology in Ukraine. New Developments in Mining Engineering 2015: Theoretical and Practical Solutions of Mineral Resources Mining, 27-32. https://doi.org/10.1201/b19901-6

3. Naumko, I., Kurovets', I., Zubyk, M., Batsevych, N., Sakhno, B., \& Chepusenko, P. (2017). Hydrocarbon compounds and plausible mechanism of gas generation in "shale" gas prospective Silurian deposits of Lviv paleozoic depression. Geodynamics, 1(22), 26-41. https://doi.org/10.23939/jgd2017.01.026

4. Samoylov, V. (2017). Planning of the industrial and hydrogeological research at the final stage of hydrocarbon deposits development. Visnyk of V.N Karazin Kharkiv national university-series geology geography ecology, (46), 45-49. https://doi.org/10.26565/2410-7360-2017-46-05

5. Melnikov, V., \& Gennadinik, V. (2018). Cryodiversity: the world of cold on the Earth and in the solar system. Philosophy and Cosmology, (20), 43-54. https://doi.org/10.29202/phil-cosm/20/4

6. Kvenvolden, K.A. (1993). Gas hydrates - Geological Perspective and Global Change. Reviews of Geophysics, 31(2), 173-187. http://dx.doi.org/10.1029/93rg00268

7. Carrol John (2009). Natural Gas Hydrates. A Guide for Engineers, $2^{\text {nd }}$ Ed. Oxford: Gulf Publishing.

8. Shnyukov, E., Gozhik, P., Krayushkin, V., \& Klochko, V. (2007). On the Eve of the World of Submarine Methane Hydrate Extraction. Reports of National Academy of Sciences of Ukraine, (6), 125-134.

9. Chilingar, G.V., \& Yen, T.F. (1978). Bitumens, asphalts, and tar sands. New York, Elsevier Science.

10. Canada's Oil Sands, Opportunities and Challenges to 2015. An Energy Market Assessment, May 2004, National Energy Board, Canada, 108.

11. Briggs, P.J., Baron, P.R., \& Fulleylove, R.J. (1988). Development of Heavy-Oil Reservoirs. Journal of Petroleum Technology, 206-214.

12. Sadler, K.W. (1995). An EUB Review of In Situ Oil Sands Bitumen Production. SPE paper 30240- MS presented at SPE International Heavy Oil Symposium, 19-21 June, Calgary, Alberta, Canada.

13. Arens, V., Babichev, A., Bashkatov, A., Gridin, O., Khrulev, A., \& Khcheyan, G. (2007). Borehole Hydro-Mining. Proc. Manual: Mining Book.

14. Rehbinder, G. (1980). A Theory about Cutting Rock with Water Jet. Rock Mechanics, 12(3-4), 247-257. http://dx.doi.org/10.1007/bf01251028

15. Bondarenko, V., Sai, K., Prokopenko, K., \& Zhuravlov, D. (2018). Thermodynamic and Geomechanical Processes Research in the Development of Gas Hydrate Deposits in the Conditions of the Black Sea. Mining of Mineral Deposits, 12(2), 104-115. https://doi.org/10.15407/mining12.02.104

16. Bondarenko, V., Kovalevska, I., Astafiev, D., \& Malova, O. (2018). Examination of Phase Transition of Mine Methane to Gas Hydrates and their Sudden Failure - Percy Bridgman's Effect. Solid State Phenomena, (277), 137-146. https://doi.org/10.4028/www.scientific.net/SSP.277.137

17. Helgerud, M.B. (2001). Wavespeeds in gas hydrate and sediments containing gashydrate: A laboratory and modeling study. Ph.D. Stanford Univ. Press. Stanford, Calif. 
18. Pedchenko, M., \& Pedchenko, L. (2017). Analysis of gas hydrate deposits development by applying elements of hydraulic borehole mining technology. Mining of Mineral Deposits, 11(2), 52-58. https://doi.org/10.15407/mining11.02.052

19. Pedchenko, L., \& Pedchenko, M. (2012). Substantiation of Method of Formation of Ice Hydrate Blocks with the Purpose of Transporting and Storage of Hydrate Gas. Naukovyi Visnyk Natsionalnoho Hirnychoho Universytetu, (1), 28-34. 